\title{
Correction to: Beyond the Economic Gaze: Childbearing During and After Recessions in the Nordic Countries
}

\section{L. Comolli ${ }^{1}$. G. Neyer ${ }^{2} \cdot$ G. Andersson ${ }^{2} \cdot$ L. Dommermuth ${ }^{6} \cdot$ P. Fallesen ${ }^{2,4}$. M. Jalovaara ${ }^{5} \cdot A$. Klængur Jónsson ${ }^{2} \cdot M . K$ Kolk $^{2} \cdot$ T. Lappegård $^{3}$}

Accepted: 22 February 2021 / Published online: 10 March 2021

(c) The Author(s) 2021

\section{Correction to: European Journal of Population https://doi.org/10.1007/s10680-020-09570-0}

In the article published online 17 October 2020 the affiliation of Lars Dommermuth was erroneously given as 'University of Oslo, Oslo, Norway. However Lars Dommermuth is senior researcher at:

The Research Department at Statistics Norway (SSB), Oslo, Norway.

The original article has been corrected.

Publisher's Note Springer Nature remains neutral with regard to jurisdictional claims in published maps and institutional affiliations.

The original article can be found online at https://doi.org/10.1007/s10680-020-09570-0.

C. L. Comolli

chiara.comolli@unil.ch

1 University of Lausanne, Quartier UNIL-Mouline, Bâtiment Géopolis, Bureau : 5321, CH-1015 Lausanne, Switzerland

2 Stockholm University, Stockholm, Sweden

3 University of Oslo, Oslo, Norway

4 ROCKWOOL Foundation, Copenhagen, Denmark

5 University of Turku, Turku, Finland

6 The Research Department at Statistics Norway (SSB), Oslo, Norway 